\title{
High Inspiratory Pressure Alarm Device
}

National Cancer Institute

\section{Source}

National Cancer Institute. High Inspiratory Pressure Alarm Device. NCI Thesaurus. Code C49817.

A device designed to signal the occurrence of a high pressure event associated with a mechanical ventilation device. 